\title{
FINITE ELEMENT STUDY OF COMBINED THERMAL-WIND LOADING EFFECTS ON RAINSCREEN FACADE SYSTEM
}

\author{
${ }^{1}$ Darragh, M., ${ }^{1}$ Jenaban, M., ${ }^{2}$ Chong, P.L.* ${ }^{2}$ Habibi, H. \\ ${ }^{1}$ Sotech Architectural Façade Systems, Unit 2, Traynor Way, Peterlee, SR8 2RU \\ ${ }^{2}$ School of Computing, Engineering \& Digital Technologies, Teesside University, \\ Middlesbrough, TS1 3BX
}

* Corresponding Author: p.chong@tees.ac.uk TEL: +44 01642384420

\begin{abstract}
Sotech is a leading manufacturer of bespoke rainscreen cladding and architectural façade systems, where aluminium cladding façade is of particular interest. Necessarily, the design of façade system is required to meet safety and stability requirements, which is conventionally the deformation due to wind load. However, it is questionable that the thermal load is normally neglected, particularly during an extremely hot weather. For the benefit of Sotech in terms of design reliability, it is important to factor in thermal load to acquire for comprehensive deformation results. Consequently, the aim of this study is to investigate how the aluminium cladding façade reacts to a combined loading, which is the combination of wind load and thermal load, using finite element analysis. In the model, the gravitational load will be considered, and the combination of wind loads up to $50 \mathrm{mph}$ and thermal loads from $-30^{\circ} \mathrm{C}$ to $35^{\circ} \mathrm{C}$ are applied to the aluminium cladding panel. Typically, the material is defined as aluminium alloy, which is easy to manufacture and has a high strength to weight ratio. The key finding is that addition of thermal load to wind load is not necessarily topping up the deformation, since there can be an effect of wind load being negated by thermal load. This study lays a foundation for Sotech to improve the design standard.
\end{abstract}

Keywords: Finite element analysis; Combined loading; Wind loading; Thermal loading; Aluminium cladding façade.

\section{Introduction}


Rainscreen cladding has been in use since around the 1950's with one of the first being a 30story skyscraper called the Alcoa building in Pennsylvania in 1953. As the years have progressed research, testing, and validation of design has taken place to show the amazing ability of rainscreen cladding to protect a buildings external material from the harsh elements. In modern construction, rainscreen cladding is the industry standard because, as well as having great weather protection, it has the potential to be aesthetically pleasing due to being available in a wide variety of finished, textures and depths.

This is illustrated wonderfully in Figure 1 - Discovery Quay, Salford. As well as different colour combinations, there are a plethora of designs and shapes than can be produced to make the building standout in a sea of dull high rises. Within the rainscreen façade industry most of, if not all the research is primarily based on façade panels under wind load or the whole building under Computational Fluid Dynamics (CFD) analysis (Kültür et al., 2019; Izadyar et al.,2020). This is to provide evidence that the panels will not fail under extreme climactic condition, the impact of new buildings on air movement around existing structures, the effectiveness of the HVAC (Heating, Ventilation, and Air Conditioning) systems, and the effectiveness of natural ventilation to name but a few.

Lo et al. (2020) found that where the building envelope is a single layer interface, the extreme wind load is usually consistent with the wind loading on a solid surface. This study talks about the effect of wind load when applied to a solid façade and how the force can be reduced with the use of porous facades. This is also wind as the stressor alone, with no inclusion of a thermal stressor and how it will affect the aluminium cladding panel (Lo et al., 2020). Ding and Kareem (2020) look at how wind interacts with the buildings overall form and how the stress can be reduced with the use of dynamic facades, which will also contribute to the internal thermal comfort of the building's occupants.

A dynamic façade is where the building exterior can change shape to account for different wind direction and speed or sun position for internal lighting. As with before this paper focuses on wind load and how the buildings facades can be changed to reduce the stress the façade panels have to deal with, with no mention of an external thermal irradiance, or a combined loading effect on the panels (Ding \& Kareem, 2020). Abdelaziz et al. (2021) talks primarily about how to reduce wind induced vibration at low speeds that cause vortex shedding and flutter induced instabilities, one again this is primarily about wind alone and doesn't consider the effects of a combined load situation. 
As with the study of wind load, CFD analysis mainly focuses an individual load, such as the wind around a building or the thermal effects on ventilation without using combined loading (Abdelaziz et al., 2021). Blocken et al. (2009) mainly focuses on what affect the wind has on the convective heat transfer coefficient around the building without considering its structural affect as a thermal stressor for stress and deflection of the façade rainscreen alone. This also does not have a combined loading effect on the building (Blocken et al., 2009). Brandl et al. (2014) primary focus is to study thermal behaviour and airflow characteristics inside the façade elements, with a detailed analysis of photovoltaic modules and their impact on airflow and thermal behaviour inside the cavity. The study does not investigate the affect that a combined load has on the stress and deflection of the panels (Brandl et al., 2014). Iken et al. (2019) mainly looks at the greenhouse effect during summer and ways to control thermal comfort with the use of a 2D CFD simulation. It is looking at the thermal and energetic behaviour of smart material to coat the façade and the air cavity thickness with no investigation of combined loading and its effect on the structure of the building's façade (Iken et al., 2019). Kahsay et al. (2019) focus on how balconies, mullions or egg-crate shading elements on these façade systems interact with the external microclimate and what affect this has on the CHTC, which can be quite significant. However, this paper does not look at what affect the CHTC has on the structural integrity and does not look at how a combined load of wind and thermal affect the façade (Kahsay et al., 2019).

Zheng et al. (2021) mainly focuses on wind flow patterns and surface pressure and what affect balcony, and balcony geometries have on wind speed and pressure on the façade. The current studies mainly focus on the deformation due to wind loads, and thermal effects only be considered in the aspect of thermal comfort instead of loading effect to the aluminium cladding facade. The thermal loading acting on the aluminium cladding façade tends to be neglected. In turn there is no research showing how the combined effect of wind and thermal loadings acting on the aluminium cladding façade. Consequently, the research objective is to incorporate the thermal loading to wind loading acting on the aluminium cladding façade to investigate the combined loading effect. The results analysis will cover individual loadings and combined loading. Simsolid allows for rapid design iterations as the program produces simulations without meshing. This decreases the time needed to run simulations because this decreases the need to use local mesh control to higher stressed areas. In section 2 the discussion will be on how the finite element process works and how the data for sim solid is calculated. In section 3 the results of the simulations will be presented in graphical form and the finding will be 
discussed in greater depth. Finally, a conclusion will follow summarising the findings (Zheng et al., 2021).

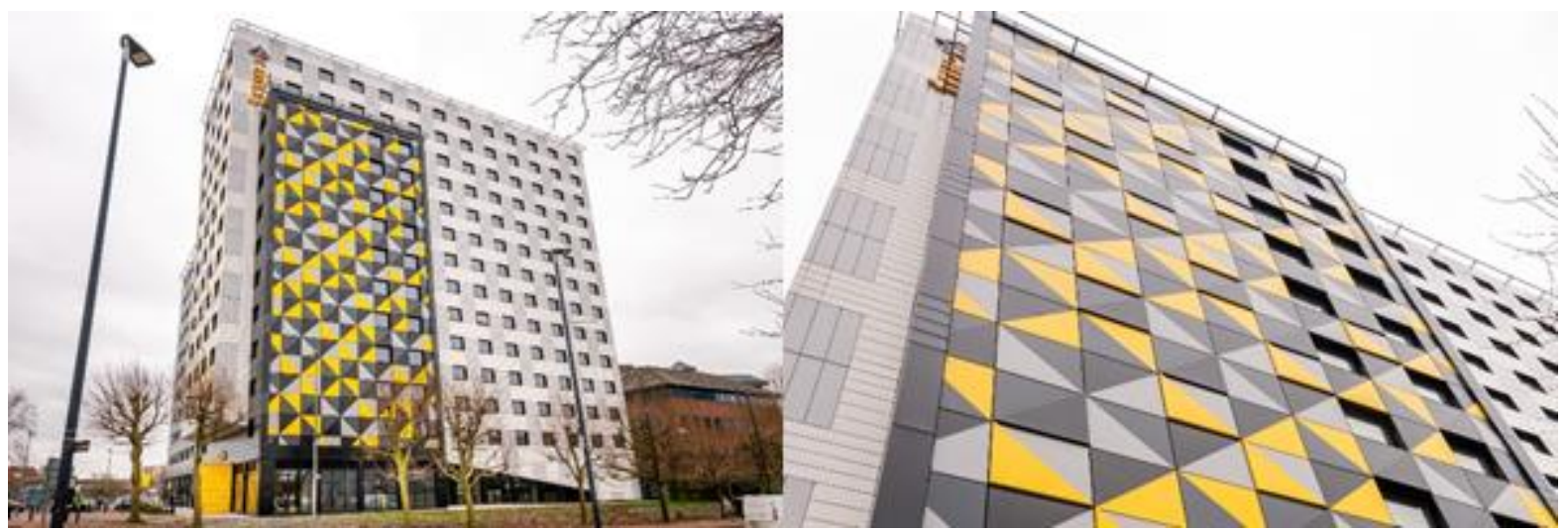

Figure 1. Discovery Quay, Salford

\section{Materials and Methods}

Of particular interest of Sotech, the loading effect of the largest façade panel is studied, where the face width is $1350 \mathrm{~mm}$ and the face height of $3850 \mathrm{~mm}$. The input setting to the finite element software, Altair Simsolid are wind loads subject to the wind speed from $2 \mathrm{mph}$ to $60 \mathrm{mph}$, surrounding temperature ranging from $-30^{\circ} \mathrm{C}$ to $35^{\circ} \mathrm{C}$ and the radiation heat flux seasonal data from (Ma et al., 2018).

\subsection{Determination of Convection Coefficient}

To get the data required for the simulation a set of calculations need to be done. The main data point that needs calculating is the convective heat transfer coefficient (h). To calculate $h$, firstly we need to calculate the Reynolds number and the Nusselt number. The Reynolds number in Equation 1 is a dimensionless number that determines if a fluids flow is laminar or turbulent (Cengel, 2002). It does this by producing a ratio between the inertial forces and the viscous forces, and this number will determine if the flow is laminar or turbulent.

$$
R e=\frac{\text { Inertia Forces }}{\text { Viscous Forces }}=\frac{V * L}{v}
$$

In this equation $\mathrm{V}$ is the wind speed, $\mathrm{L}$ is the length of the panel and $\mathrm{v}$ is the kinematic viscosity of air at the stated temperature. The Nusselt number is the number equating to the heat transfer through a fluid as a result of convection relating to conduction through the same fluid (Cengel, 
2002). The Nusselt number is a function that relates to the Reynolds number and the Prandtl Number. The two equations for the Nusselt number can be seen in Equation 2 and Equation 3.

$$
\begin{gathered}
\text { Laminar: } N u=\frac{h L}{k}=0.664 * \operatorname{Re}_{L}^{0.8} * \operatorname{Pr}^{\frac{1}{3}} \\
\qquad e_{L}<5 * 10^{5} \\
\text { Turbulent: } N u=\frac{h L}{k}=0.037 * \operatorname{Re}_{L}^{0.8} * \operatorname{Pr}^{\frac{1}{3}} \\
0.6 \leq \operatorname{Pr} \leq 60,5 * 10^{5} \leq \operatorname{Re}_{L} \leq 10^{5}
\end{gathered}
$$

In these equation Re is the calculated Reynolds number, Pr is the Prandtl Number, $\mathrm{h}$ is the conductive heat transfer coefficient, $\mathrm{L}$ is the length, and $\mathrm{k}$ is thermal conductivity. The Prandtl number and the rest of the data that is required for the calculations comes from a data table showing the properties of air at 1 atmosphere. Convective heat transfer happens when a fluid encounters a solid surface such as an aluminium panel and their temperatures are different and can be described as the ratio between the heat flux and the driving force for the flow of heat which can be seen in Equation 4.

$$
h=\frac{N u * L}{K}
$$

During this research and simulation, the Reynolds number does not exceed $5 * 10^{5}$ so Equation 2 will be used. Firstly, the Nusselt number will be calculated by the right-hand side of Equation 2 because the correct information is available from the calculations and tables. From here we can rearrange the left-hand side and middle of the equation to get equation 4 . From this equation the convective heat transfer coefficient is calculated which will give us all the information needed to run the simulation in Altair Simsolid.

\subsection{Finite Element Procedures on Combined Loading}


The model to be tested will be first draw in Autodesk Inventor in several parts. The first part being the panel that will be used for the simulations. This can be seen in Figure $\mathbf{2}$ and Figure 3.

In Figure 2, the different coloured section that has been applied to the front of the panel. This is there to simulate the air which later will have a heat flux applied to it. In Figure 3, the rear of the panel is displayed with top hats affixed to it. These are there to increase the stiffness of the panel and help the aluminium cladding panel resist failure in harsher wind conditions. The spacings are usually equidistant no matter how many are needed, so in this instant the top hats are $550 \mathrm{~mm}$ apart.

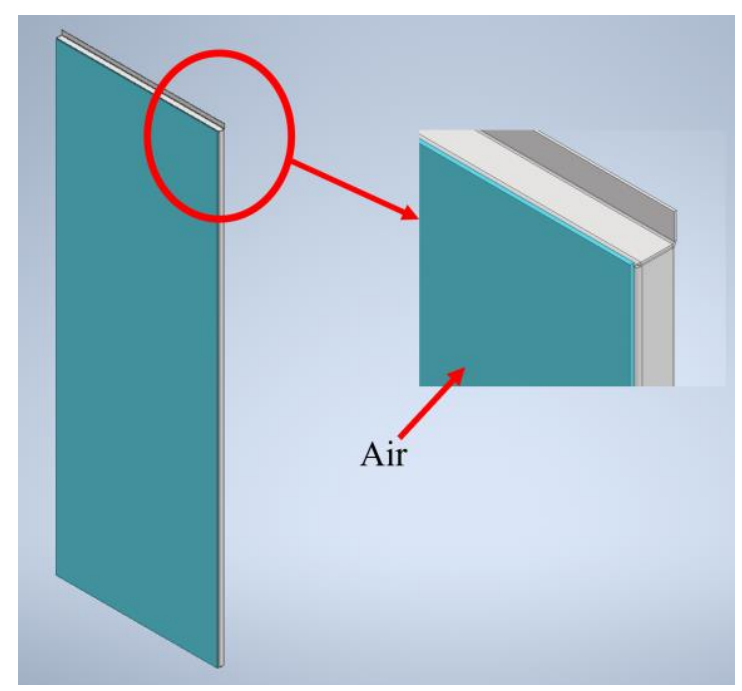

Figure 2. Modelled panel with air front

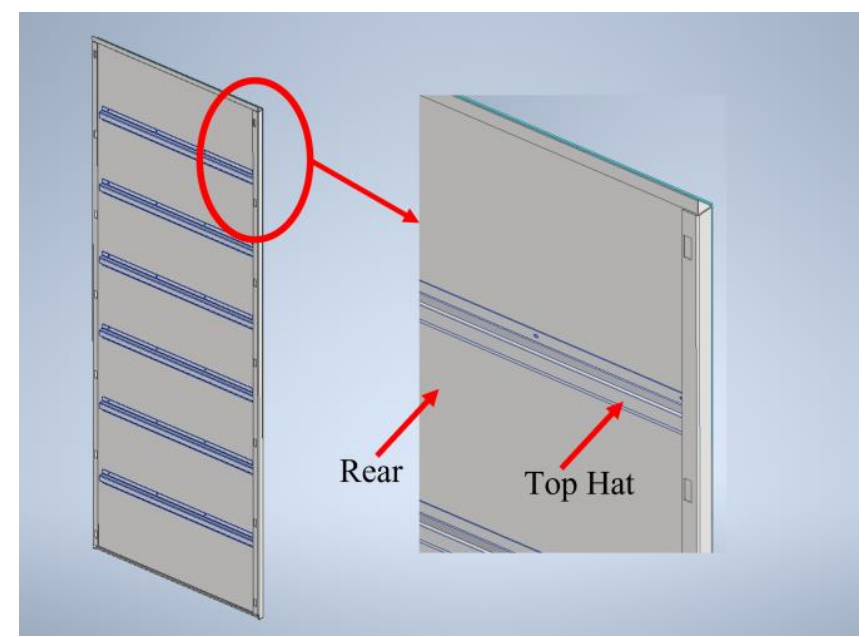

Figure 3. Modelled panel with air rear 
Once the part is imported into Altair Simsolid, as will all FEA Simulations, constraints are needed to fix the model in place as it would be in the real world. For this model the top hook slots are fixed in such a way as they cannot move, denoted by the red lines in Figure 4. The rest of the equally spaced hooks below are only fixed in the $\mathrm{X}$ and $\mathrm{Z}$ direction. This is to simulate the panel being hooked in but leaving a small gap to allow for the panel to expansion. For the thermal analysis, the calculated heat flux is applied to the front face of the slab simulating the air which can be seen in Figure 5. The thermal convection value is placed on the back of the slab and interfaces with the front of out panel to simulate the heat transfer between the two mediums.

For the wind pressure, this is applied to the front face of the panel as a negative pressure shown in Figure 5. Sotech recognise that the worst loading condition is when the aluminium cladding façade encounter negative pressure. The negative pressure can be explained by Bernoulli's principle. In this case, the speed of air flow at the front face is highly greater than the rear face, which causes the high pressure pushing from the rear face. This has been recognised as a worst scenario, where the top hat design cannot support the opposite loading direction on the aluminium cladding façade.

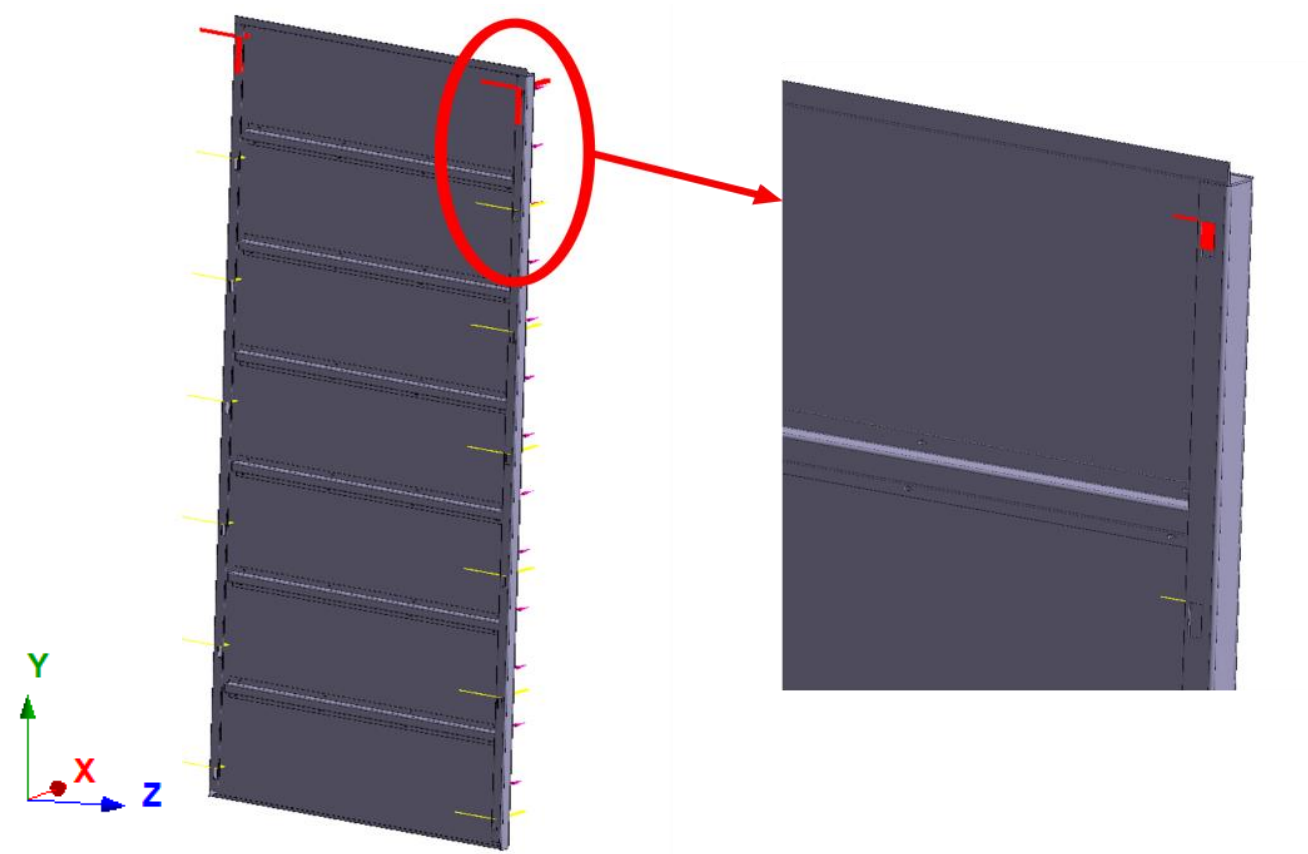

Figure 4. Top slots fixed with no movement 


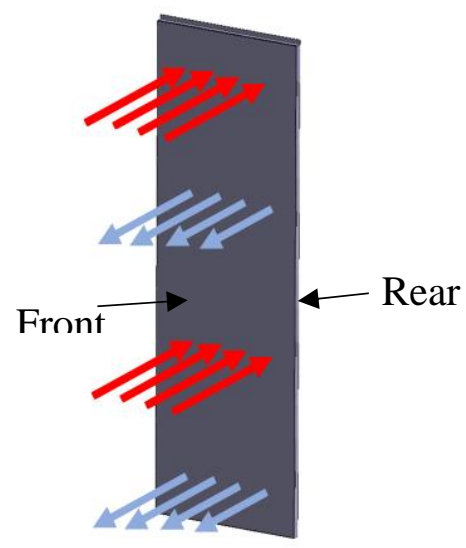

Figure 5. Heat flux applied to face of air (red) and negative pressure applied to panel face

Figure 6 shows the results of thermal stress alone with a wind speed of $50 \mathrm{mph}$, a $35^{\circ} \mathrm{C}$ temperature, and a heat flux of $100 \mathrm{kWh} / \mathrm{m}^{2}$. With solar irradiance as a stressor alone the panels displacement is higher at the bottom of the panel due to the way it is constrained. The top hook slots are holding the panel in place alone which allows the panel to expand down without inducing too much stress which would happen if all the hooks didn't have a gap for thermal expansion. The max deflection is $0.3 \mathrm{~mm}$ which is within the allowable deflection of this panel which would be $15 \mathrm{~mm}$, which is an industrial standard from the Centre for Window and Cladding Technology (CWCT) guidelines.
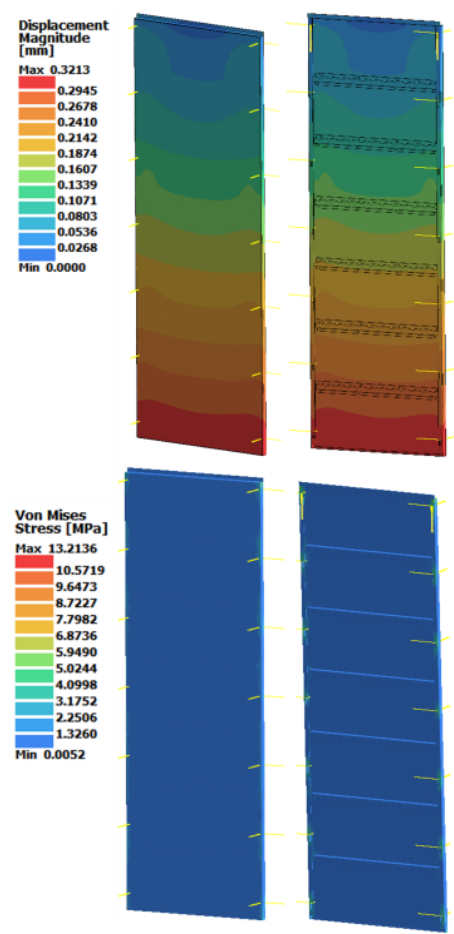

Figure 6. Thermal FEA simulation results with $50 \mathrm{mph}$ wind at $35^{\circ} \mathrm{C}$ with a heat flux at 100 $\mathrm{kWh} / \mathrm{m}^{2}$ 
Figure 7 is the same as Error! Reference source not found. but with the wind pressure applied to the panel in the negative direction to simulate aluminium cladding getting pulled off the building. As before the maximum allowable deflection is $15 \mathrm{~mm}$ and with the combined load the maximum deflectionis $1.3 \mathrm{~mm}$. The deflection is more evenly spread across the panel due to the wind pressure being applied in the negative direction from the face to simulate pulling the panel off the building.
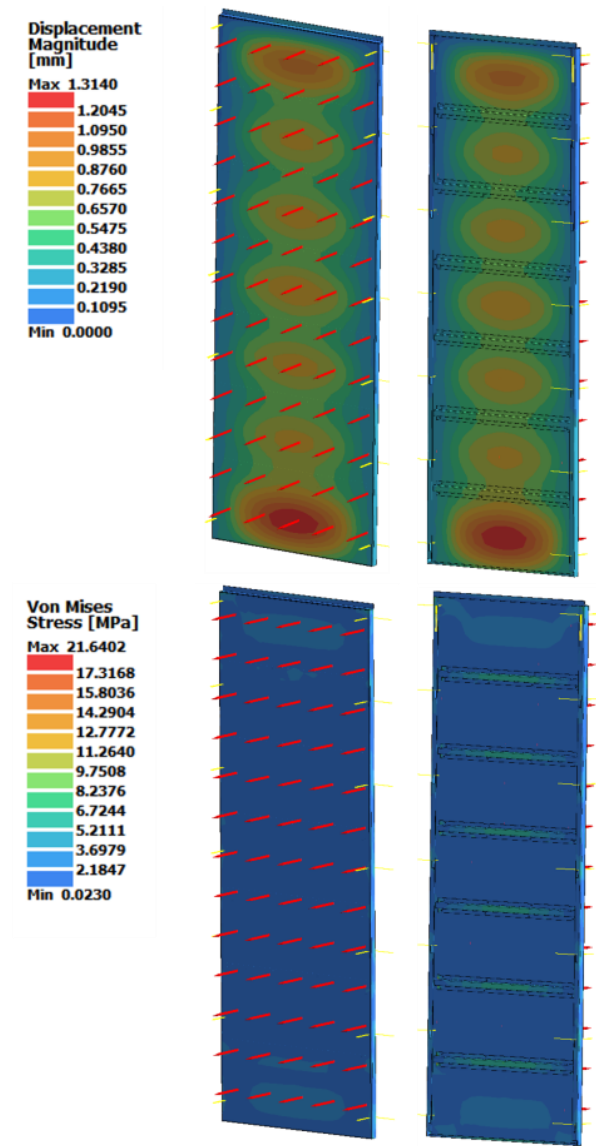

Figure 7. Combined FEA simulation results with $50 \mathrm{mph}$ wind at $35^{\circ} \mathrm{C}$ with a heat flux at $100 \mathrm{kWh} / \mathrm{m}^{2}$

\section{Results \& Discussion}

\subsection{Deflection and Stress Results}

Initially the simulations were run with thermal alone at different temperatures to simulate the weather around each of the four weather seasons from Ma et al. (2018) research. These temperatures range from $1{ }^{\circ} \mathrm{C}$ to show the effects of minimal thermal stress up to $30^{\circ} \mathrm{C}$ to simulate a very hot day for the north of England (Ma et al, 2018). 
The thermal effect on stress and deflection alone at $1^{\circ} \mathrm{C}$ can be seen in Figure 8. The maximum stress is less than $2.5 \mathrm{MPa}$, which is far below the yield stress and the maximum deflection of $0.023 \mathrm{~mm}$ is very small in relation to the allowable deflection stipulated in (CWCT) guidelines. With all of them, no matter what the wind speed, being between $2 \mathrm{MPa}$ and $2.5 \mathrm{MPa}$ with very small deflection. $1{ }^{\circ} \mathrm{C}$ was used to simulate when temperatures are very low and an average heat flux across the winter months.

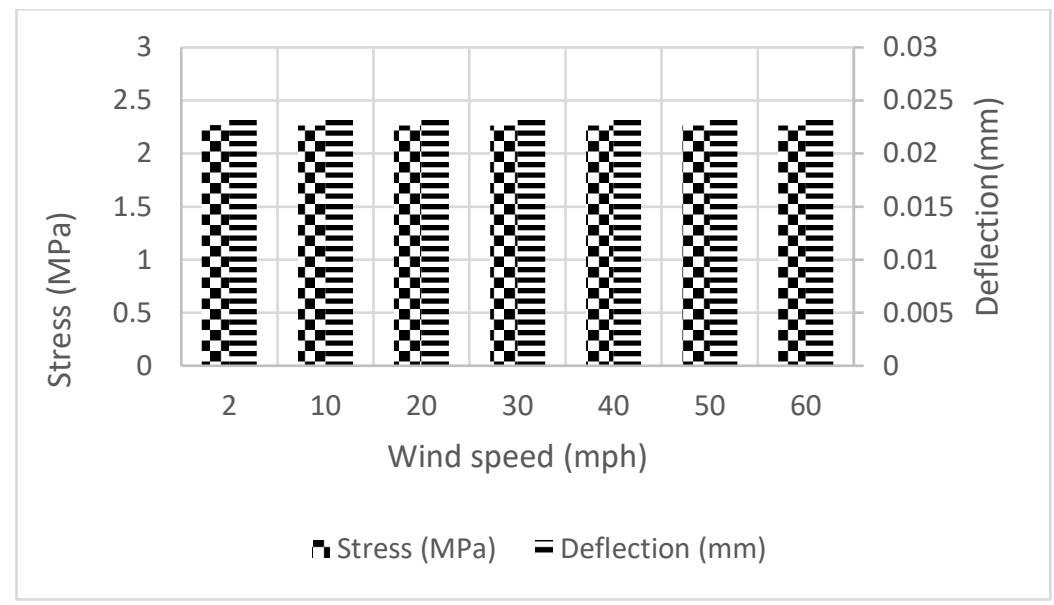

Figure 8. Thermal effect alone at $1^{\circ} \mathrm{C}$ with a heat flux of $46.3 \mathrm{~W} / \mathrm{m}^{2}$. The convective heat transfer coefficient changes with wind pressure

As with $1{ }^{\circ} \mathrm{C}$ the thermal effect on stress and deflection at $15^{\circ} \mathrm{C}$ is very small with the stress being around 6MPa and a negligible deflection of $0.14 \mathrm{~mm}$ which can be seen in Figure 9. This is below the $15 \mathrm{~mm}$ allowable deflection. $15^{\circ} \mathrm{C}$ was used for the average temperature across the spring months.

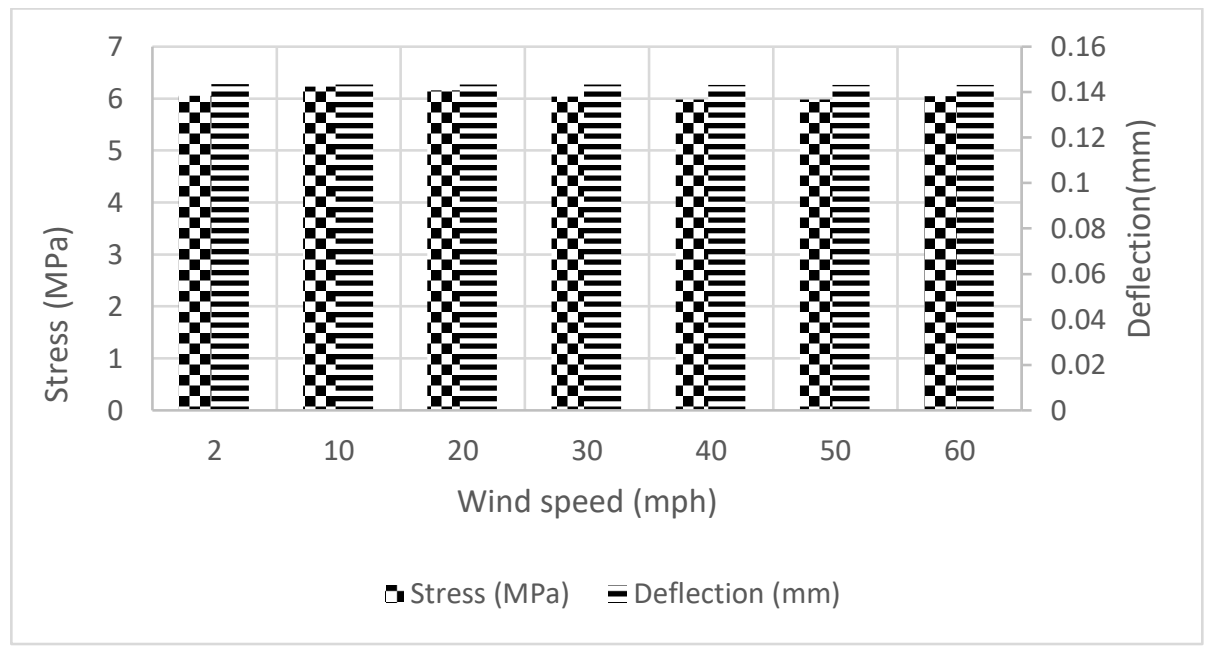

Figure 9. Thermal effect alone at $15^{\circ} \mathrm{C}$ with a heat flux of $138 \mathrm{~W} / \mathrm{m}^{2}$. The convective heat transfer coefficient changes with wind pressure 
Even at $30^{\circ} \mathrm{C}$ the stress and deflection are low which is shown in Figure 10. This is showing a sign that the thermal stress isn't a large stressor on the material. $30^{\circ} \mathrm{C}$ was used as this will be a worse case across the summer months.

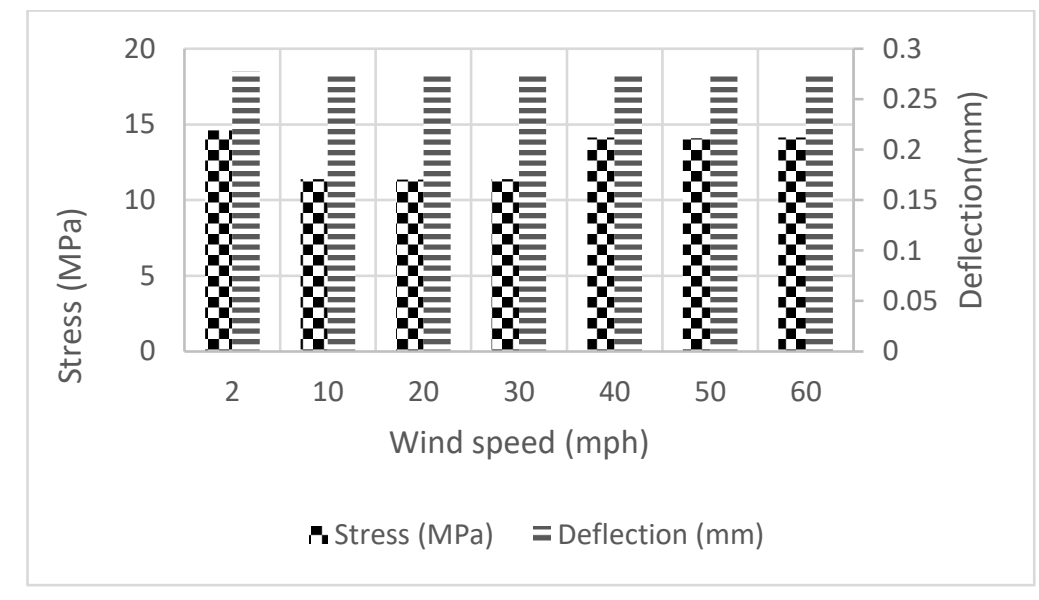

Figure 10. Thermal effect alone at $30^{\circ} \mathrm{C}$ with a heat flux of $190 \mathrm{~W} / \mathrm{m}^{2}$. The convective heat transfer coefficient changes with wind pressure

As with the other simulation the thermal stress alone at $10^{\circ} \mathrm{C}$ is very small shown in Figure 11, which is far below the yield stress. $10^{\circ} \mathrm{C}$ was used as this is the average temperature of the autumn months. Visually if we just consider the thermal effect as a thermal stress on the façade panels the stress and deflection do not increase drastically with a large increase in temperature. Without a wind load present on the panels in a combined load situation the result could be misleading as one can greatly affect the other in certain circumstances. Because of this the investigation will go further and look at the effect of combined load of wind and thermal has on the façade panels. This gives a more realistic loading condition on the façade panels.

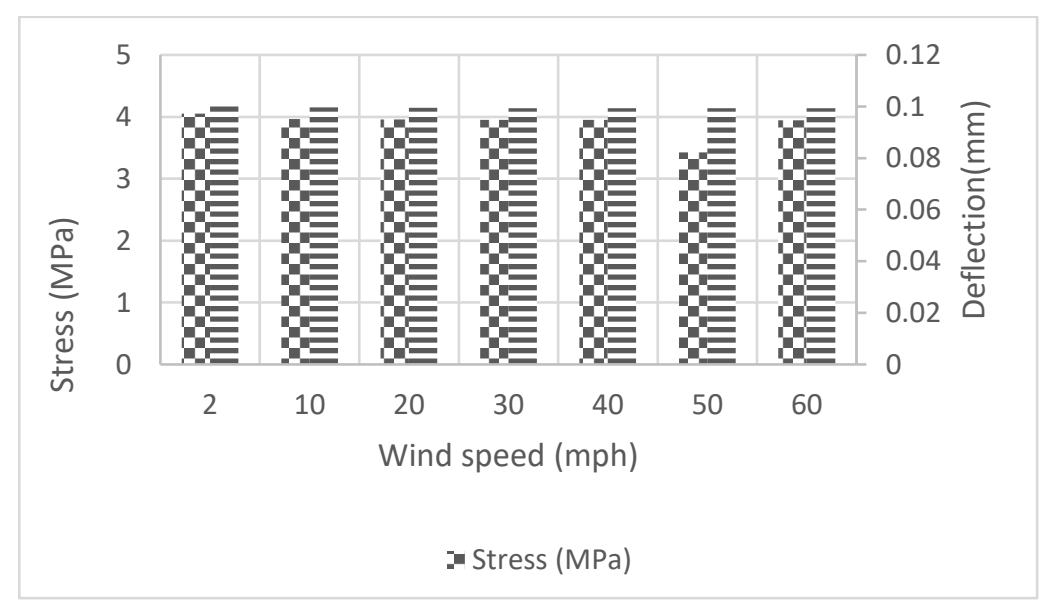

Figure 11. Thermal effect alone at $10^{\circ} \mathrm{C}$ with a heat flux of $46 \mathrm{~W} / \mathrm{m}^{2}$. The convective heat transfer coefficient changes with wind pressure 
The wind forces used throughout these simulations come from the Beaufort Wind force scale. Number 9 was used which is classed as a strong or severe gale around $50 \mathrm{mph}$ (Department of Energy \& Climate Change, 2016). When introducing the wind load on the panel, at a low wind speed of 5mph the combined load doesn't deviate much from the thermal load alone shown in Figure 12. This shows that at a low wind speed the panel isn't affected too much.

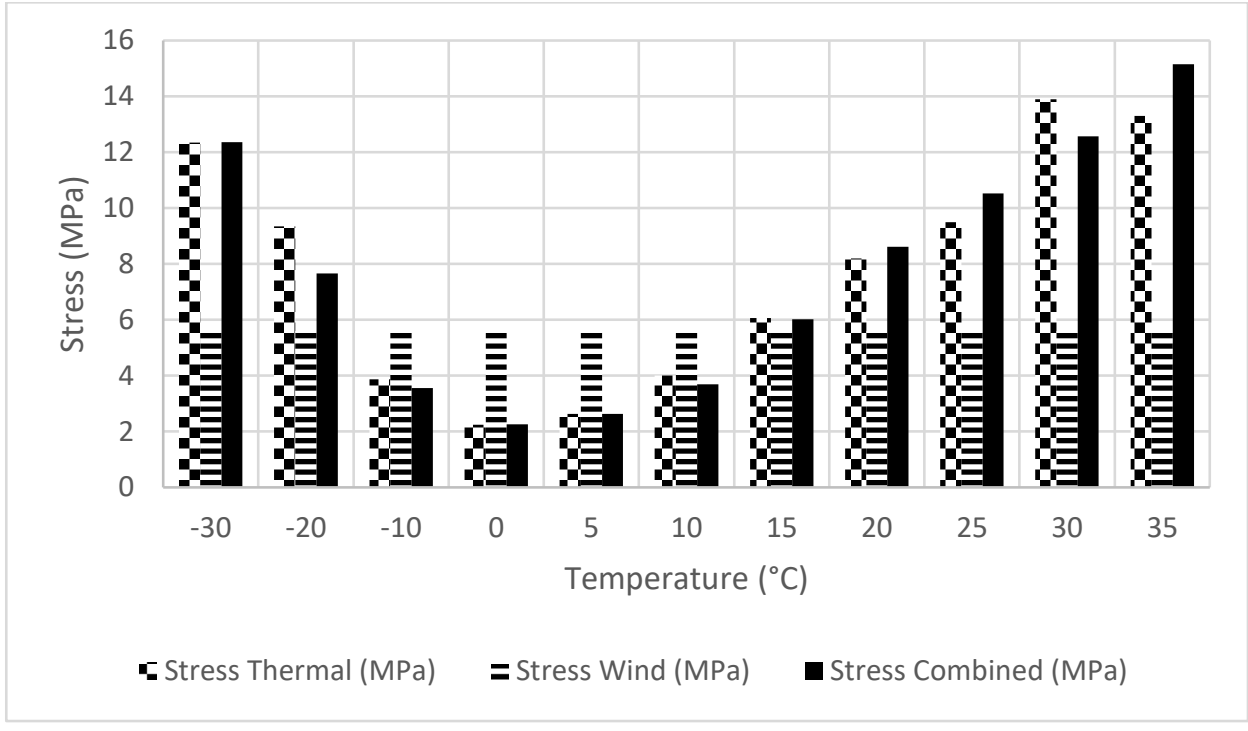

Figure 12. Stress comparison at $5 \mathrm{mph}$

As the wind speed and subsequently the pressure on the panel increases, the deflection on the panel has started to increase up until $35^{\circ} \mathrm{C}$ where the combined load deflection results are lower than the thermal stress alone as shown in Figure 13.

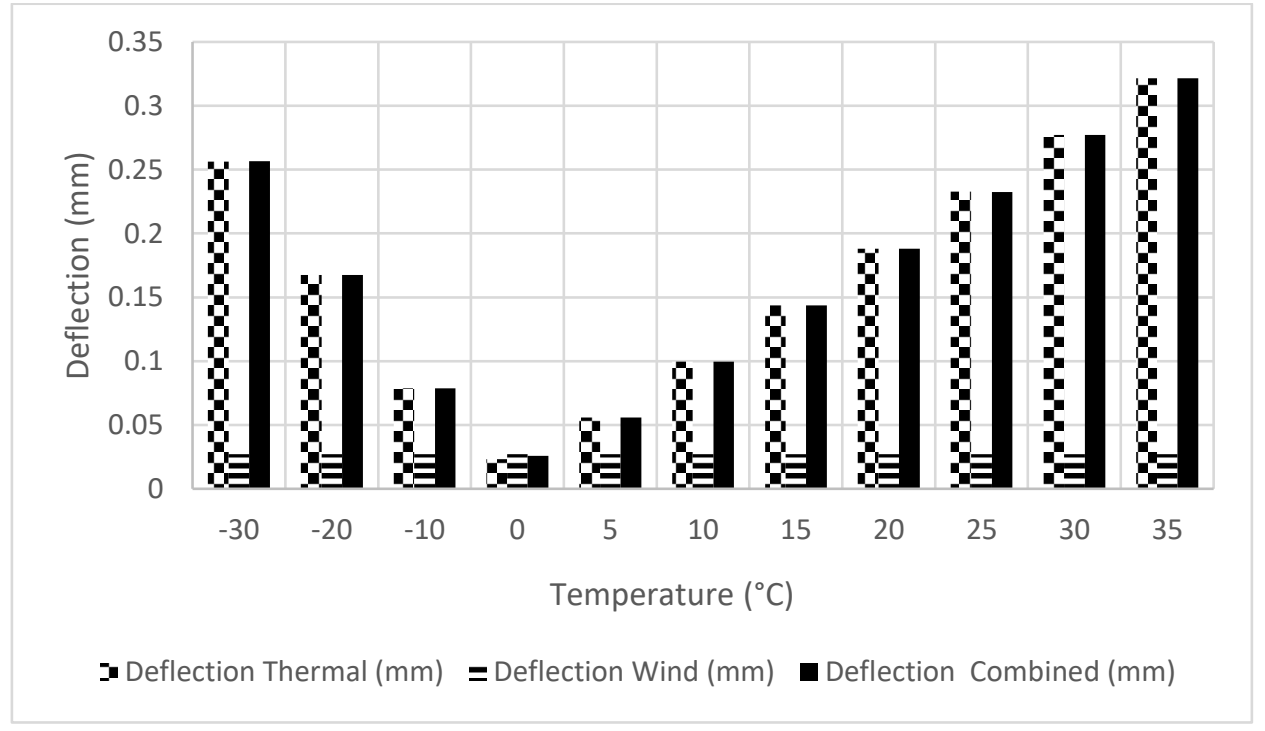

Figure 13. Deflection comparison at $5 \mathrm{mph}$ 
Figure 14 illustrates the maximum stresses encountered by the façade panel at the wind speed of $25 \mathrm{mph}$. In the cases of $-30^{\circ} \mathrm{C}, 25^{\circ} \mathrm{C}$ and $30^{\circ} \mathrm{C}$, the respective maximum combined stresses are higher than the individual stresses due to thermal loading and wind loading. This could be due to the stress due to the thermal loading is higher than that of wind loading. For the remaining of the cases, the maximum combined stresses are lower than one of the individual stresses.

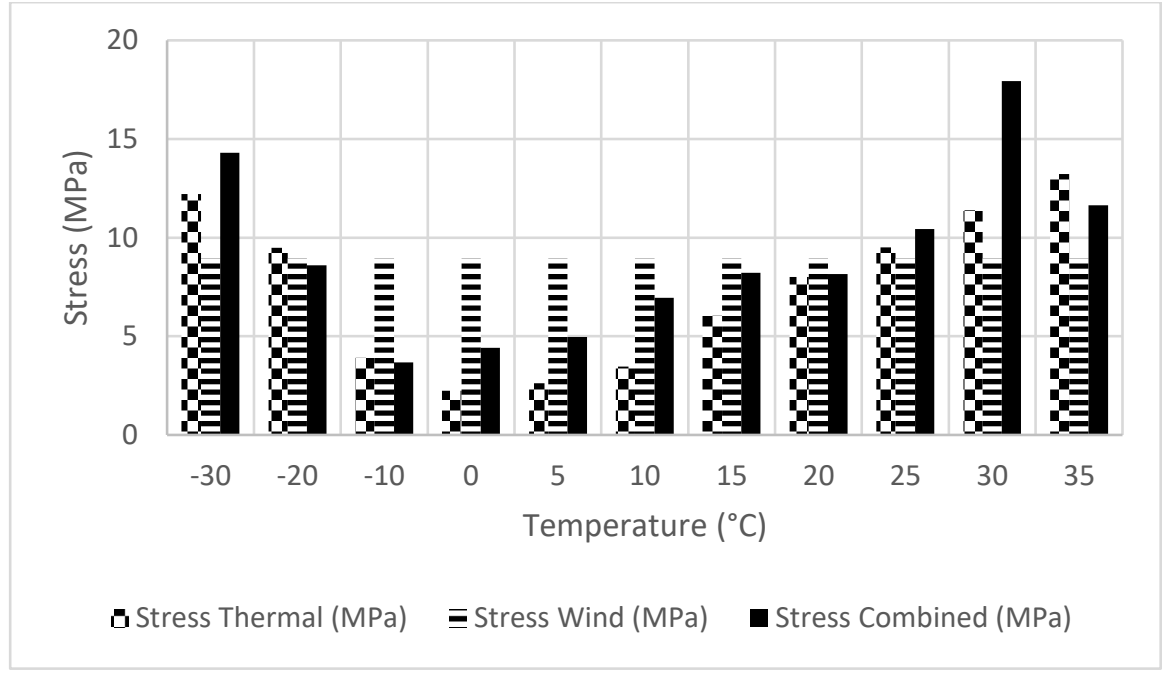

Figure 14. Stress comparison at $25 \mathrm{mph}$

Figure 15 shows the maximum deflections of façade panel due to thermal loading, wind loading and combination of wind and thermal loadings. In the cases of $-10^{\circ} \mathrm{C}$ and $0^{\circ} \mathrm{C}$, the respective maximum deflections due to combine load are slightly lower than that of wind load. This could be due to the contraction effect of the panel at such low temperatures.

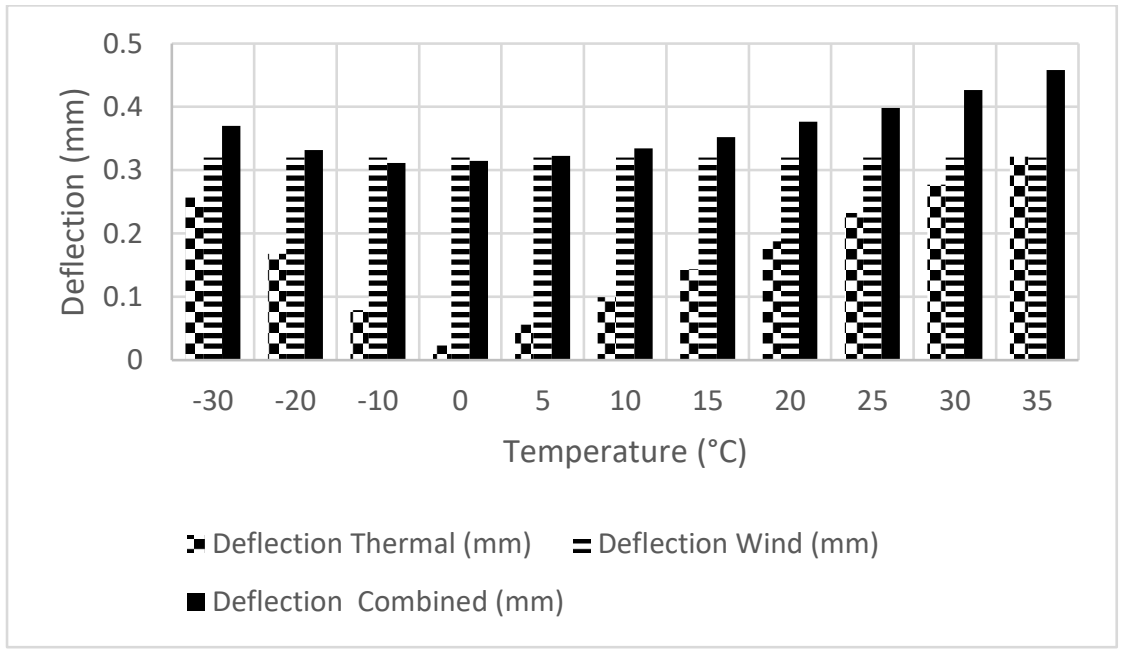

Figure 15. Deflection comparison at 25mph 
As the wind speed drastically starts to increase the combined deflection in Error! Reference source not found. is very similar but the stress on the panel Figure $\mathbf{1 6}$ is much lower in the combined loading than the wind alone for most temperatures.

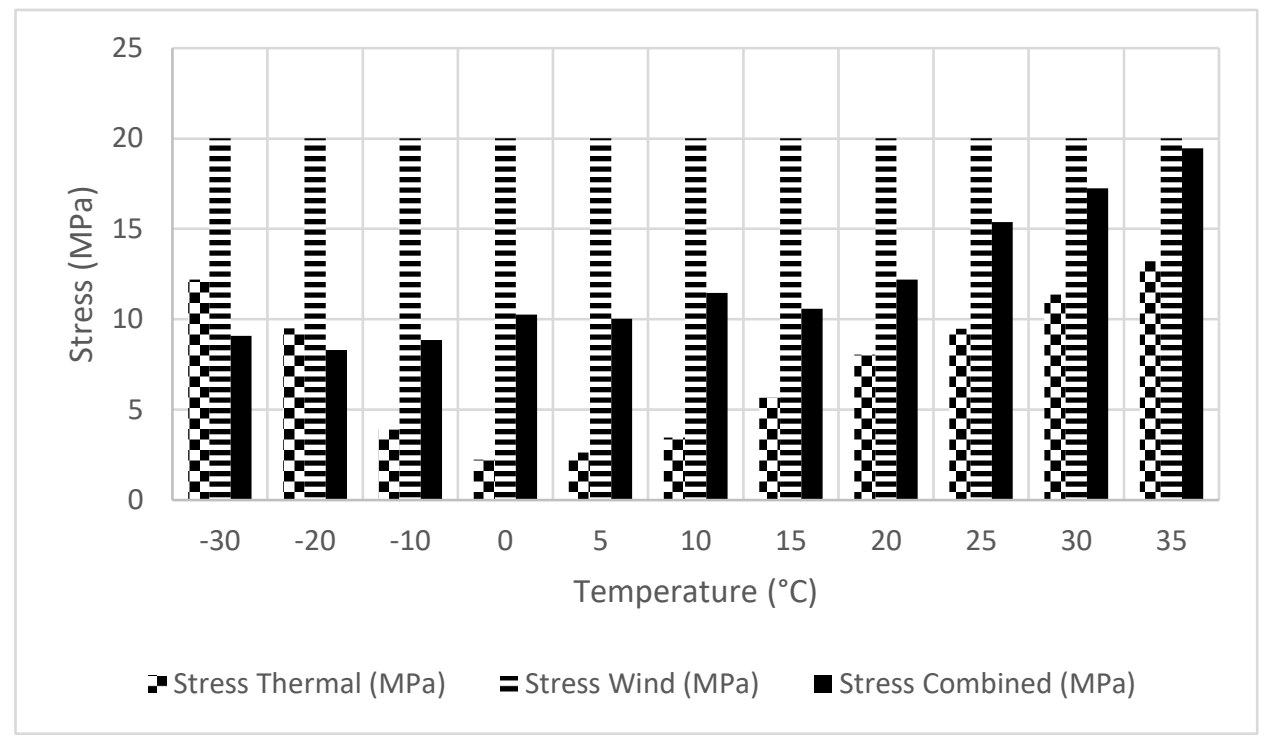

Figure 16. Stress comparison at $37.5 \mathrm{mph}$

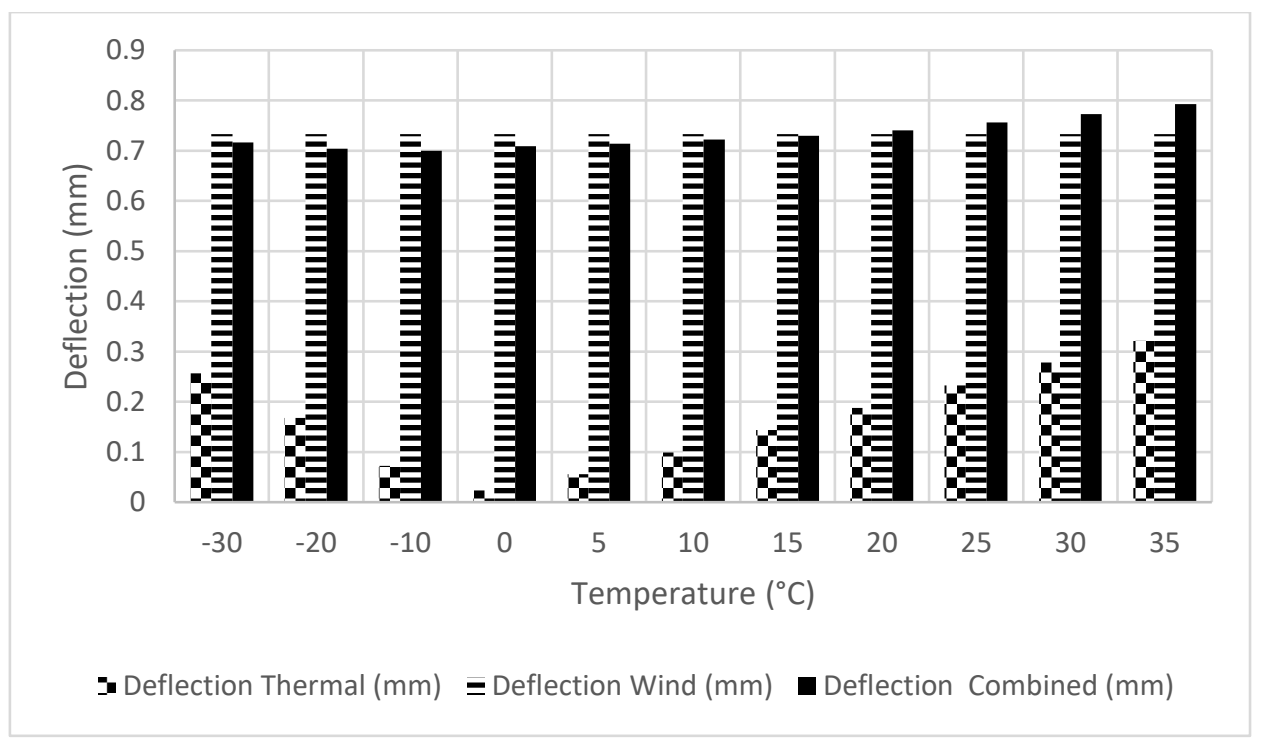

Figure 17. Deflection comparison at $37.5 \mathrm{mph}$

As with before the deflection is very similar to the wind deflection alone across all temperatures. On the other hand, the stress in the combined load is drastically reduced in comparison to the wind load alone shown in Figure 18. The temperature between $-30^{\circ} \mathrm{C}$ and 
$35^{\circ} \mathrm{C}$ as this gives us a wide range of temperature data to look at and see if there are and trends. The wind speeds were selected as just under $50 \mathrm{mph}$ was the highest average speed recorded in the past ten years, and a selection was used from $5 \mathrm{mph}$ upwards to get a variety of data.

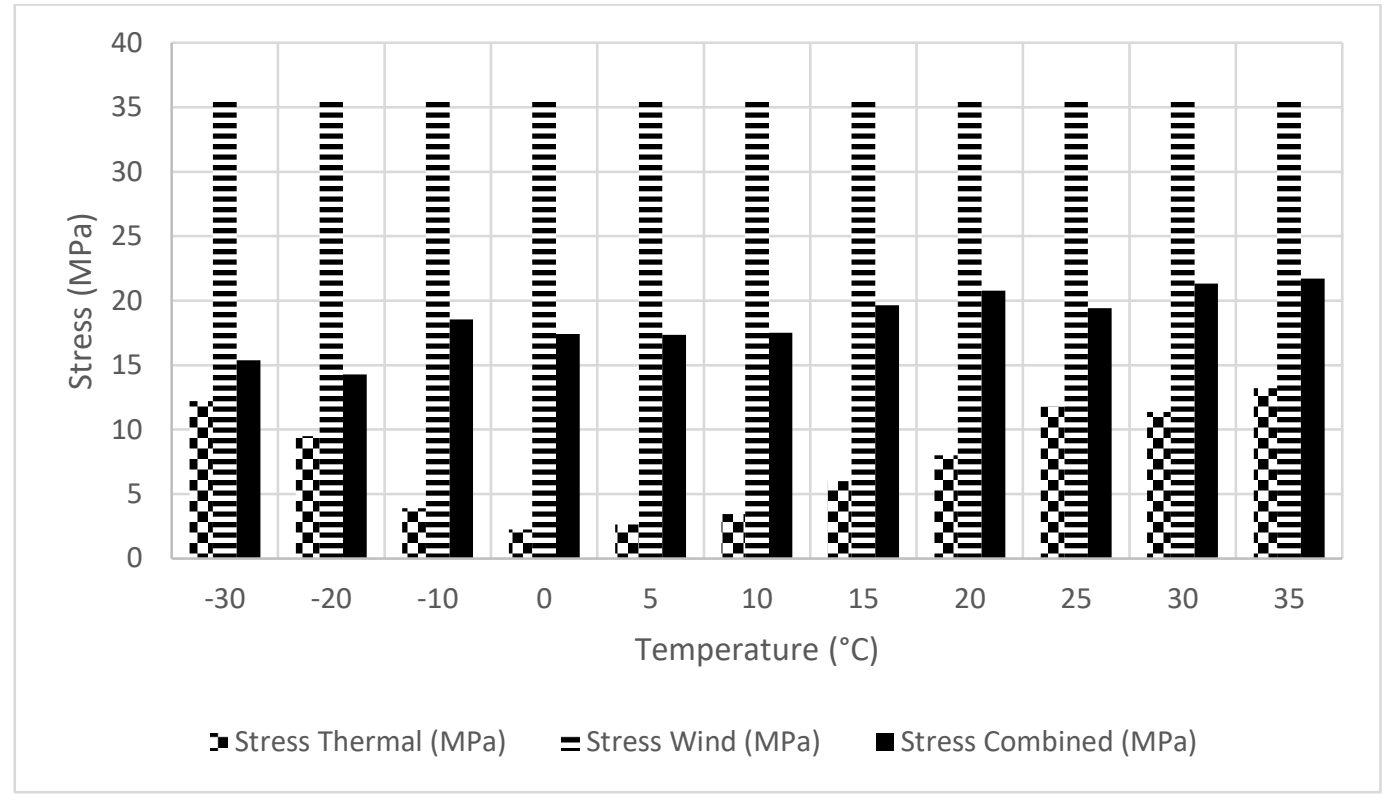

Figure 18. Stress Comparison at 50mph

Looking into Figure 19, the maximum deflections on the façade due to combined loading is consistently lower than the individual wind loads. This could be due to the high wind speed of $50 \mathrm{mph}$ and resulting high level of wind energy remove the heating effect.

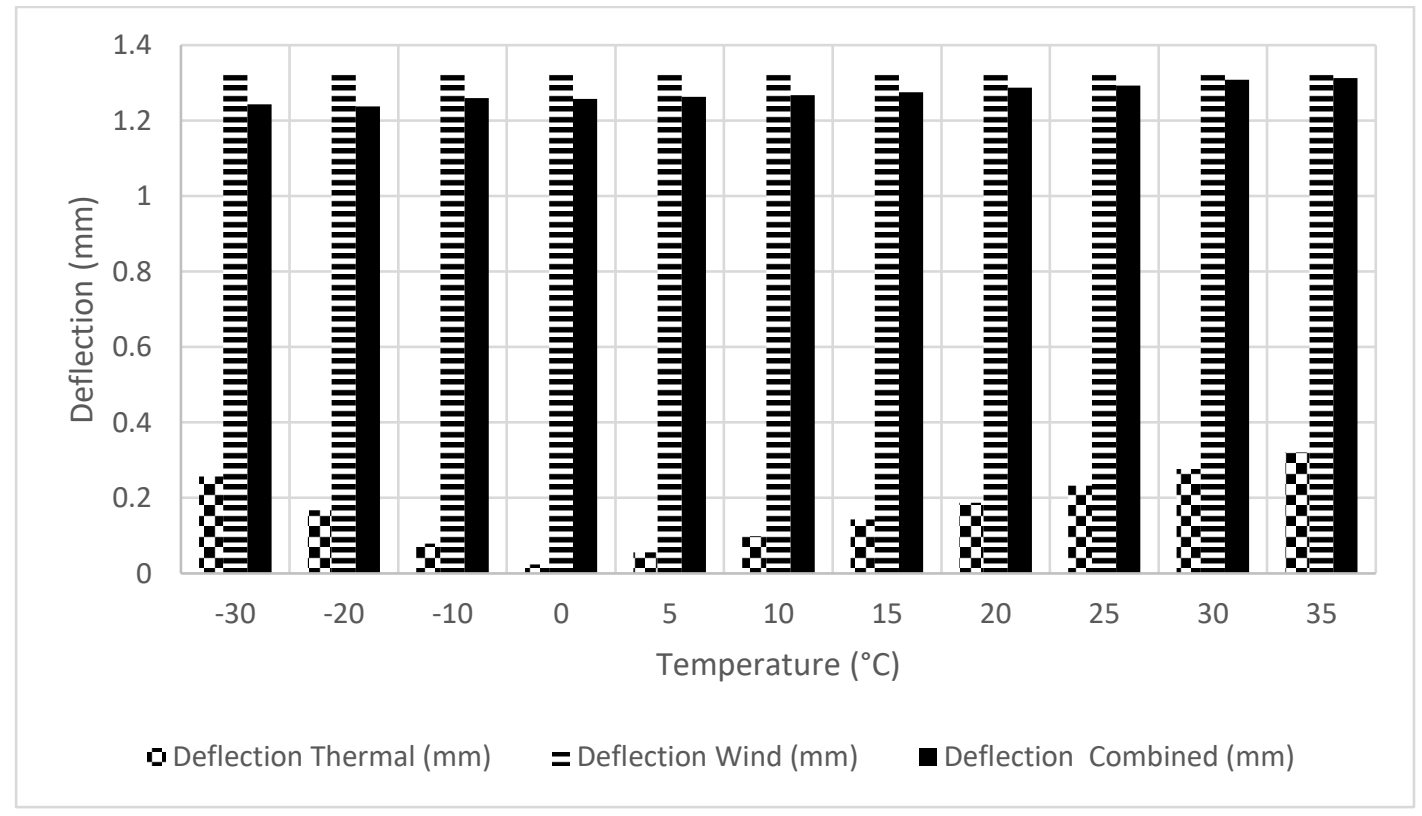

Figure 19. Deflection comparison at 50mph 


\subsection{Discussions}

With the thermal load on the panel alone the stress and deflection are quite low showing that the major stress on the panel is the wind load and the pressure produces on the panel. The trend as the wind speed increased is that the deflection was very similar but on the other hand, with the increase in speed the combined load is drastically reduced. This changes as the temperature increases but at a higher wind load, the temperature also needs to be high for the combined load to be similar. The reason the combined load is greatly reduced compared to the wind load alone is that some of the energy from the wind is used as a forced convection pulling the heat away from the panel and cooling it down. This is like how a CPU cooler works or the radiator cooler in your car. With the use of forced convection, the panel is stressed less but the deflection is very similar. Because of the way metal atomic structures are, once they are heated up the electrons start to move around and collide. With the addition of a wind load this will be reducing the number of collisions as it pulls heat away from the panel and it turn reducing the stress in the panel.

\section{Conclusion}

Going into this research the general thought was that a combined load situations results would have been close to adding thermal load and wind load together. However, the results of aluminium cladding façade shows that the combined load effect can be smaller than individual wind load effect. This is because the wind energy not entirely contribute to the façade panel, and part of the wind energy has been consumed on removing heating effect. Therefore, it can be concluded that the combined load effect is not just adding the wind load effect and thermal load effect. Some challenges were encountered during the process including calculating the convective heat transfer coefficient and certain limitations of the software. To calculate the convective heat transfer coefficient several equations where needed meaning the process was much longer than anticipated. As the software cannot simulate the sun the solar irradiation was used with some assumptions made about its value. From the simulations that have been done the results have shown that the wind pressure alone is the largest stressor on the panel. As well as finding out that solar alone doesn't have a large impact on the panel, at higher temperatures some of the energy in the wind is used to pull heat away from the panel reducing the overall stress experienced by the aluminium cladding panel. 


\section{Acknowledgement}

I would like to thank Sotech for giving me the opportunity to pursue this research project. I would also like to extend my sincere thanks to Teesside University and the European Regional Development Fund for their Growth Associate Programme.

\section{References}

Abdelaziz, K. M., Alipour, A., and Hobeck, J. D. (2021). A smart façade system controller for optimized wind-induced vibration mitigation in tall buildings. Journal of Wind Engineering and Industrial Aerodynamics, 212, 104601.

Blocken, B., Defraeye, T., Derome, D., and Carmeliet, J. (2009). High-resolution CFD simulations for forced convective heat transfer coefficients at the facade of a low-rise building. Building and Environment, 44(12), pp. 2396-2412.

Brandl, D., Mach, T., Grobbauer, M., and Hochenauer, C. (2014). Analysis of ventilation effects and the thermal behaviour of multifunctional façade elements with 3D CFD models. Energy and Buildings, 85, pp. 305-320.

Cengel, Y. A. (2002). Heat Transfer, A Practical Approach. New York: McGraw-Hill.

Department of Energy and Climate Change. (2016). Offshore energy SEA3 - environmental baseline. UK Offshore Energy Strategic Environmental Assessment.

Ding, F., and Kareem, A. (2020). Tall buildings with dynamic facade under winds. Engineering, 6(12), pp. 1443-1453.

Iken, O., Dlimi, M., Agounoun, R., Kadiri, I., and Sbai, K. (2019). Thermal and energy performance investigation of a smart double skin facade integrating vanadium dioxide through CFD simulations. Energy Conversion and Management, 195, pp. 650-671.

Izadyar, N., Miller, W., Rismanchi, B., and Garcia-Hansen, V. (2020). Impacts of façade openings' geometry on natural ventilation and occupants' perception: a review. Building and Environment, 170, 106613.

Kahsay, M. T., Bitsuamlak, G. T., and Tariku, F. (2019). CFD simulation of external CHTC on a high-rise building with and without façade appurtenances. Building and Environment, 165, 106350. 
Kültür, S., Türkeri, N., and Knaack, U. (2019). A holistic decision support tool for facade design. Buildings, 9(8), 186.

Lo, Y. L., Wu, Y. T., Fu, C. L., and Yu, Y. C. (2020). Wind load reduction effects on inner buildings by exterior porous façades. Building and Environment, 183, 107148.

Ma, Z., Bao, H., and Roskilly, A. P. (2018). Feasibility study of seasonal solar thermal energy storage in domestic dwellings in the UK. Solar Energy, 162, pp. 489-499.

Zheng, X., Montazeri, H., and Blocken, B. (2021). CFD analysis of the impact of geometrical characteristics of building balconies on near-façade wind flow and surface pressure. Building and Environment, 200, 107904. 